\title{
Online Continuing Professional Development: An integrative approach
}

\author{
Angelica Risquez ${ }^{1}$, Dara Cassidy ${ }^{2}$, Gearóid Ó Súilleabháin ${ }^{3}$, Roisin Garvey ${ }^{3}$, Sinead \\ Spain 1 \\ ${ }^{1}$ Centre for Teaching and Learning, University of Limerick, Ireland, ${ }^{2}$ Online Education, \\ Royal College of Surgeons, Ireland, ${ }^{3}$ Department of Technology Enhanced Learning, Cork \\ Institute of Technology, Ireland.
}

\begin{abstract}
This paper reports on the design, development, delivery and evaluation of an online continuing professional development $(C P D)$ course in the area of online teaching by three Irish Higher Education Institutes (HEIs). The course was developed in the context of a nationally coordinated effort to promote CPD of those that teach in Higher Education through digital badges. Survey results suggest a very high overall satisfaction rate with the course as a whole, increased levels of knowledge and confidence in relation to teaching online, and also intended transference to practice. While the external motivator of demonstrating engagement through the digital badge arose in the surveys and focus groups, it did not feature particularly strongly. Implications for CPD are discussed in relation to internal and external drivers and motivations around CPD for higher education teachers, and the need for opportunities for participants to interact and engage in the manner reminiscent of a community of practice approach.
\end{abstract}

Keywords: continuing professional development (CPD); digital badges; online teaching; higher education. 


\section{Introduction}

The use of digital technologies continues to expand within higher education globally. With this growing use comes a need for teaching staff to be supported and encouraged in their use of these technologies to create innovative and effective learning. This paper reports on the design, development, implementation and evaluation of an open course aimed at those getting started with online teaching, which was delivered by distance by three Irish Higher Education Institutes (HEIs): Hibernia College, University of Limerick, and Cork Institute of Technology. The three HEIs received funding from the National Forum for the Enhancement for Teaching and Learning to develop a CPD offering on the topic as part of its National Digital Badge System ${ }^{1}$. The curriculum of the open course covered designing online units and assessments, developing educational content and media, and creating a positive online environment for learning. An iterative, collaborative approach was taken to the design of the learning material and associated media for a fully online delivery through Moodle, Articulate Rise $^{\oplus}$ and additional standard multimedia editing tools.

Underpinning the philosophy of the course, it was recognised that an understanding of the student perspective and what it is like to study online is crucial. A number of videos featuring online students talking about what they like and what they find challenging about online learning were created for the course. The perspectives of some lecturers and tutors who have been involved in online teaching were also integrated. Most importantly, best practice of online teaching was modelled through a number of synchronous and asynchronous activites, and in addition to the content there were, notably, extensive online activities and opportunities for online communication and collaboration.

The course was divided into four sections. First, it focuses on designing modules for the online environment. In the second section, some online assessment options are presented and discussed. Next, it focuses on online activities and content creation; in particular looking at open education resources and approaches to media creation. The last section focuses on online facilitation and interaction and includes some strategies for engaging students in the online space and building a learning community.

The eight week online implementation of this open course was a notable success in terms of its popularity, its positive reception and in terms of its mainstream impact across a number

\footnotetext{
${ }^{1}$ The National Professional Development Open Courses in Ireland has been developed by the National Forum for the Enhancement of Teaching and Learning in close collaboration with the higher education sector to create a means of recognising and acknowledging those committed to ongoing professional development in teaching and learning. The first phase of the national professional development digital badge initiative in 2017 saw the design of 15 open-access programmes with national digital badges to the HE sector, each covering a relevant topic to academic's professional development, and equaling around 25 hours of participant effort. These open courses have been developed against nationally agreed criteria, thus enabling staff to have achieve recognition and mobility within their professional development journey and career advancement.
} 
of HEIs. As an initiative of the National Digital Badge System the course also allowed successful graduates to claim a specially designed digital badge to recognize their learning.In the context of a growing but fragmentary body of literature on approaches to and models of online academic CPD (see, e.g.,Donnelly, 2015; Kennedy, 2005; King, 2002; Klein \& Ware, 2003; Riding, 2001) the current paper presents findings with regard to five key research questions (RQ): (1) what are the motivations underpinning the participation of lecturers in this course?; (2) did this online professional development course increase the knowledge of lecturers about teaching online?; (3) did this online professional development course increase the confidence of lecturers about teaching online?; (4) has this course impacted the attitudes of lecturers to online teaching?; and (5) has this course impacted the teaching practice of lecturers?

\section{Methods}

A basic mixed methods approach was used to investigate the research questions outlined above. Data gathering methods consisted of a quantitative pre and post-survey, and a number of focus groups. The mixed methods approach represented a deliberate effort at methodological triangulation, in an attempt to examine the experiences, motivations and outcomes of our learners from more than one methodological or epistemological standpoint. All but one of the 37 participants who were offered a place in the course consented to take part in the research and completed the pre-course survey. 26 responded to the post course survey, representing $76 \%$ of the 34 participants who completed the course. A total of 10 participants took part in the focus groups on completion of the course. Thematic analysis of qualitative focus group data was undertaken based on guidelines from Braun and Clarke (2006). Participation on the research phase of this course was at all times voluntary and anomymous, and ethical clearance was obtained through Hibernia College, and recognized by the other participating institutions.

\section{Results}

\subsection{Pre and post survey results}

The results of the pre-survey revealed high levels of experience of online learning as student $(86 \%)$, and as a teacher (67\%). Digital confidence levels were also high or very high (56\%), and most were either already involved to some extent in online or blended delivery or were planning to do so in the near future. When asked what motivated them to participate, the main reasons given were related to a general desire for professional development, enhancing their knowledge of learning design for the online context, learning how to develop content for online delivery and finding out more about engaging students online. Others made reference to planning, assessment delivery and support. Only two people specifically mentioned the 
digital badge that was associated with the course. As seen in figure 1 below, participants were positive about the effectiveness online delivery as a mode of teaching and learning. They were also generally positive about the possibilities for engagement, interaction and collaboration.

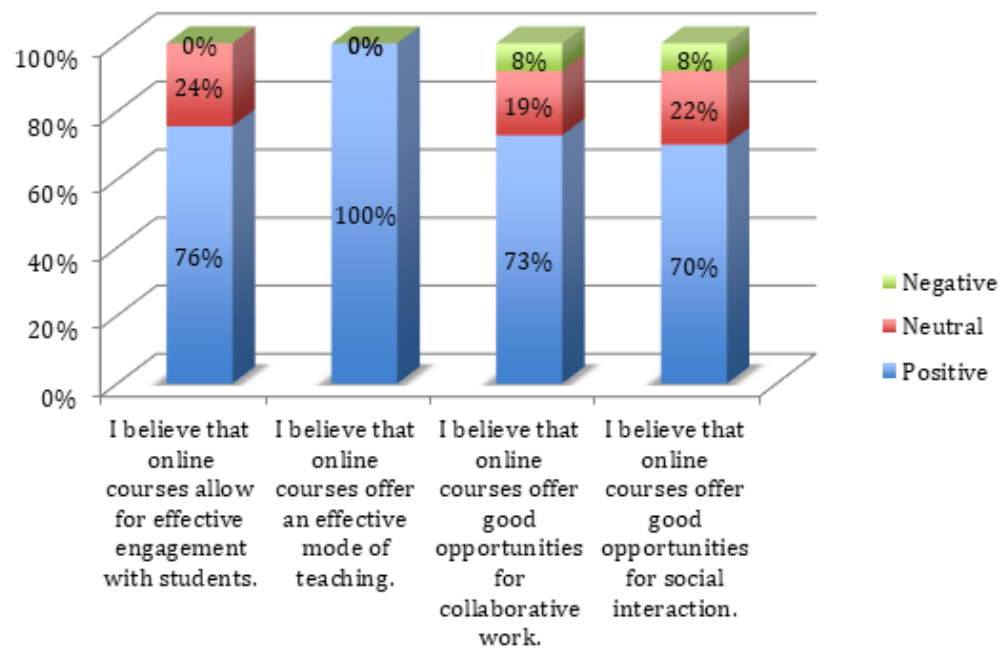

Figure 1. Attitudes to online teaching and learning

Asked about their satisfaction with the course, all 26 respondents of the post-survey were satisfied $(42 \%)$ or very satisfied $(58 \%)$. The teaching methodologies used in the course were rated as effective (46\%) or very effective (42\%). All stated they would implement what they learned in the course, which was in relation to the practice and experience of using various tools, the overall enhanced knowledge of what's involved in online and blended learning, the confidence they gained from participating in the course and the alignment with their more general plans to deliver online/blended courses. In terms of the impact of the course, $80 \%$ of respondents claimed the course had changed the way they think about online learning. The results were overwhelmingly positive in relation to the confidence levels in terms of design, content development, assessment and facilitation of online teaching. Out of 26 survey participants, a majority affirmed they were confident or very confident when creating content for online delivery (23), designing a module for online delivery (22) designing assessment for online learning (19) and facilitating a module online (20). Most of the 23 respondents referred to the design and structure of the course as its strongest point. The discussion forum and the focus on tools were next most widely referenced items. By far the most common complaint was 'lack of time', in relation to both the timing of the course and the workload involved. Some respondents also mentioned lack of student-student interaction and specific tasks that the participants didn't enjoy. Enhancements suggested included a detailed calendar at the start of the course, more flexibility regarding the timing of the course, and a greater 
focus on encouraging student-student participation. All those who responded to the postcourse survey said they would be claiming their digital badge.

\subsection{Thematic analysis of focus groups}

Braun and Clarke's (2006) approach to thematic analysis of transcribed focus group material has proved helpful as 'an essentialist or realist method, which reports experiences, meanings and the reality of participants'. After identifying five main semantic themes (motivations to participate, engagement with the course, impact on teachers, impact on practice, and other benefits), text was coded hierarchically in two sub-levels. Most of the coded text clusters around motivations to participate (40 references) and impact on teachers (46), with the other themes gathering far less number of references. The analysis of motivations to participate in this course (RQ1), clustered around either extrinsic or intrinsic drives. Extrinsic motivations included (1) demonstrating engagement with CPD and accreditation through the digital badge; and (2) incentives, pressures and relevance to practice, including impending plans for moving courses online. Intrinsic motivators included (1) interest in the development of theoretical knowledge and practice on OT, (2) exposure to and modelling of OT, (3) exposure to new technologies and learning new digital skills, and (4) personal interest and convenience of the course at the time when it took place. Closely related to motivations to participate, a series of themes revolved around the participants' engagement with the course. These included the following: (1) their commitment to and approach to participation (which ranged from the more strategic to those who engaged at a very deep level); (2) challenges to engagement, including a perceived high workload associated with the tasks that the course consisted of; (3) insights around the development of a community of inquiry throughout the course, which was perceived by many to be the most positive and distinctive characteristic of this course; (4) their experiences with the tools or platforms (both positive and negative); and (5) the importance of teaching presence, which was at the core of the community of inquiry. The exploration of the impact that the course had on teachers revolved around how their knowledge, confidence and attitudes of OT had evolved, corresponding to RQ2, 3, and 4 respectively. The most important gains in terms of knowledge consisted of (1) exposure to and modelling of OT, (2) exposure to new technologies and learning new digital skills and (3) theory and practice of OT. New or existing attitudes developed regarding (1) acknowledgement of value of OT, (2) the need for educational and technical support, and (3) an increasing awareness and understanding of the many considerations that OT involves, with special attention to its implications for curriculum design and student and staff workload. Participants also offered their insights around their increased self-confidence as online teachers. In close relation to this, some evidence of impact on practice was gathered (thus answering RQ5), although it was widely acknowledged that these are more likely to be realised in the future. These implications included (1) promoting OT practice in their immediate context with peers and managers and (2) prompting action around OT design. In 
doing this, participants often found that the artefacts created during the completion of the course (the design of their online module and associated materials) were useful as exemplars of potential practice, and could be used to demonstrate and influence teaching practice in their context. Also, some other implications were recorded, which were somewhat unexpected. The participation in the course had a positive effect on the development of communication and writing skills, and even prompted some participants to continue CPD around OT. Others appreciated the opportunity to network between institutions and declared their increased awareness of the National Forum resources and initiatives.

\section{Discussion and conclusions}

Pre-survey responses with regard to motivation and what participants wanted from the course dovetail nicely with a number of post-survey responses and associated follow-up comments as well as with a host of intrinsic and extrinsic motivations that emerge from the analysis of focus group data. Although all participants indicate in the post-survey that they plan to claim the available digital badge, and this also arose during the focus groups, it is notable that the digital badge did not feature particularly strongly. As extrinsic rewards can conflict with or diminish intrinsic motivation (see, e.g., Deci, Koestner, \& Ryan, 1999), it seems that a balance was stroke in this occasion. The issue of accreditation arose for the design team itself in a number of ways, due to an emphasis on the award-bearing national standard-setting aspect of the course around closely-defined pre-planned outcomes and, although this was resisted, a tendency towards a technicist syllabus. The project team were keenly aware throughout the design process that external accountability (e.g.,Smyth, 1991) could work against critical and reflective inquiry which we were keen to encourage. The design team were eager also to reject a purely training and/or transmission view of academic CPD and move at least in part towards a transformative approach that left room for unplanned learning outcomes in relation to attitude, values and practice-in-context as well as procedural knowledge and technical know-how. Part of the solution in the end was to build in opportunities for participants to interact and engage through a community of practice (CoP) CPD approach (Wenger, 1999). The Getting Started course was deliberately structured to encourage participants to move from quite basic replicative tasks to producing innovative original units of e-learning and critical reflections on same. Thus, participants began with "legitimate peripheral participation" and then moved towards the centre where they created new practice. Wenger's notions around CoP as social learning systems, constructs of meaning and identity chime well with focus group comments as do, of course, numerous references to the related but distinct concept of community of inquiry (Garrison, Anderson, \& Archer, 2003).

It seems ultimately that the Getting Started CPD course charted a middle course between a context-free transmission training model offering and an open transformative CPD offering 
with no planned outcomes. In any case, the results highlight the importance of professional dialogue for professional development and the importance of providing dialogic opportunities and professional dialogue (Asghar \& Pilkington, 2018). Results do suggest CPD providers might do well to consider mixing pedagogical approaches and balancing perscribed learning goals with opportunities for learner autonomy and, most importantly, learner interaction. CPD itself, particularly CPD with external validation or based on external standards, can suggest an instructionalist and also technicist orientation but can accommodate more progressive pedagogies and approaches including coaching, mentoring, CoPs and communities of inquiry as well as learning that does not exclude or try to design out questions of context, value, identity and meaning. Traditional issues arising for CPD around learning transfer, learner engagement, consistency, quality assurance and demonstration of return on investment (ROI) may ultimately only be answered only by taking both a holistic and pragmatic approach based on a thorough knowledge of available technical and pedagogical approaches, the learning domain itself and the needs of the learner group.

\section{References}

Asghar, M., \& Pilkington, R. (2018). The relational value of professional dialogue for academics pursuing HEA fellowship AU - Asghar, Mandy. International Journal for Academic Development, 23(2), 135-146. doi:10.1080/1360144X.2017.1386566

Braun, V., \& Clarke, V. (2006). Using thematic analysis in psychology AU - Braun, Virginia. Qualitative Research in Psychology, 3(2), 77-101. doi:10.1191/1478088706qp063oa

Deci, E. L., Koestner, R., \& Ryan, R. M. J. P. b. (1999). A meta-analytic review of experiments examining the effects of extrinsic rewards on intrinsic motivation. Psychological bulletin, 125(6), 627-668.

Donnelly, R. (2015). Values informing professional practice in academic professional $\begin{array}{lll}\text { development. } & \text { Infonomics } & \text { Society(1), }\end{array}$ doi:doi:10.20533/ijtie.2047.0533.2015.0071

Garrison, D. R., Anderson, T., \& Archer, W. (2003). A theory of critical inquiry in online distance education. In M. G. Moore \& W. G. Anderson (Eds.), Handbook of Distance Education (Vol. 1, pp. 113-127). Mahwah, NJ: Lawrence Erlbaum Associates, Inc.

Kennedy, A. (2005). Models of Continuing Professional Development: a framework for analysis AU - Kennedy, Aileen. Journal of In-Service Education, 31(2), 235-250. doi:10.1080/13674580500200277

King, K. (2002). Identifying success in online teacher education and professional development. The Internet and Higher Education, 5(3), 231-246.

Klein, D., \& Ware, M. J. L. p. (2003). E- learning: new opportunities in continuing professional development. Learned publishing, 16(1), 34-46.

Riding, P. (2001). Online teacher communities and continuing professional development. Teacher Development, 5(3), 283-296. 
Online Continuing Professional Development: An integrative approach

Smyth, J. (1991). Teachers as collaborative learners : Challenging dominant forms of supervision. Milton Keynes: Open University Press.

Wenger, E. (1999). Communities of practice: Learning, meaning, and identity. Cambridge: Cambridge university press. 